\title{
High-intensity focused ultrasound for thyroid nodule ablation: the evidence to date
}

\author{
Roussanka D Kovatcheva' \\ Katja Zaletel ${ }^{2}$ \\ 'Department of Thyroid and \\ Metabolic Bone Disorders, \\ Clinical Center of Endocrinology, \\ Medical University, Sofia, Bulgaria; \\ ${ }^{2}$ Department of Nuclear Medicine, \\ University Medical Centre Ljubljana, \\ Ljubljana, Slovenia
}

This article was published in the following Dove Press journal:

Reports in Medical Imaging

7 January 2017

Number of times this article has been viewed
Correspondence: Roussanka Kovatcheva Department of Thyroid and Metabolic Bone Disorders, Clinical Center of Endocrinology, Medical University, Sofia, 2, Zdrave Street, I43 I Sofia, Bulgaria Tel +359 898608602

Email roussanka_kov@yahoo.com
Abstract: Thyroid nodules are common in occurrence and most of them are benign in nature. Some of these nodules are to be treated as they continue to grow or cause undesirable symptoms. Recently, several minimally invasive thermal ablation techniques have been introduced to overcome the complications of traditional methods such as surgery. High-intensity focused ultrasound (HIFU) is the latest advance in treatment modalities, which is a noninvasive procedure that permits localized target destruction without affecting the surrounding tissues. HIFU is currently used in the treatment of various solid malignant and benign tumors. The purpose of this review is to provide an introduction to the literature, principles, and advances of HIFU therapy of benign thyroid nodules, as well as to provide a discussion on its efficacy, complications, and future.

Keywords: thyroid nodule, high-intensity focused ultrasound, ultrasound guidance, ablation techniques

\section{Introduction}

Thyroid nodule is a palpable lump within the thyroid gland that is radiologically distinct from the surrounding parenchyma. ${ }^{1}$ Nodular thyroid disease is very common in the adult population with an approximate prevalence by palpation in $5 \%$ of women and $1 \%$ of men living in iodine-sufficient areas. ${ }^{2}$ In contrast, high-resolution ultrasound (US) can detect thyroid nodules in 19-68\% of randomly selected individuals, with higher frequencies in women and the elderly. ${ }^{3,4}$ Most of the detected nodules are asymptomatic and benign on cytology, and they are usually managed by observation and follow-up..$^{5,6}$ However, approximately $30 \%$ of nodules increase in volume, with an estimated growth of $5 \%$ each year, which can cause pressure and other symptoms. ${ }^{7,8}$ According to our experience, $40 \%$ of patients with thyroid nodules have cosmetic complaints that require treatment. ${ }^{9}$

Until recently, surgery was the most common and effective treatment for thyroid nodules, although it carries a $2-10 \%$ risk of individual complications such as hypocalcemia, transient or permanent recurrent laryngeal nerve palsy, bleeding, or postoperative infection. ${ }^{10}$ Other drawbacks such as long hospitalization, scar formation, iatrogenic hypothyroidism, and difficulty in reoperation are also possible. ${ }^{11,12}$ In the past decades, treatment with radioactive iodine has also been employed leading to a $35-50 \%$ reduction in goiter volume. ${ }^{13}$

Thyroid hormone suppressive therapy for individuals with thyroid nodules is optional, but as there is no agreement on the efficacy and safety of this method, its routine use is not recommended. ${ }^{1}$ 
Over the past decade, studies have focused on developing alternative methods to the standard treatments. Various nonsurgical, minimally invasive techniques have been developed, favoring not a removal, but only the local ablation of the thyroid nodules. Percutaneous ethanol injection has shown to be effective for cystic nodules, while its application in solid nodules is limited due to the seepage of ethanol in perinodular tissues. ${ }^{14}$ The most serious adverse effects include recurrent nerve palsy, Horner syndrome, neck hematoma, thrombosis of the ipsilateral jugular vein, necrosis of the larynx and skin, or facial dysesthesia with increased tear flow. ${ }^{5,15}$

Innovative percutaneous thermal procedures such as US-guided laser and radiofrequency or microwave ablation considerably reduce the size of thyroid nodules. ${ }^{16-18}$ Although all procedures are considered safe, transient side effects including pain, bleeding, hematoma formation, nodule rupture, fever, skin burn, and impaired vocal cord mobility have been observed. ${ }^{16,19}$ Some of the complications are associated with the insertion of a needle into the nodule and the transmission of heat in the surrounding tissues.

High-intensity focused ultrasound (HIFU) is a noninvasive procedure that allows elective thermal tissue destruction by focusing a high-energy beam onto a given target, with minimal effect on the surrounding tissues. HIFU is already used to treat a variety of solid malignant and benign tumors, including the pancreas, liver, prostate, breast, uterine fibroids, and soft-tissue sarcomas. ${ }^{20}$

Recently, HIFU was proposed for thyroid nodule ablation as well. ${ }^{21,22}$ In a human feasibility study, Esnault et al demonstrated targeted tissue destruction without any damage to neighboring structures. ${ }^{23} \mathrm{~A}$ favorable outcome has been observed also in patients with primary or secondary hyperparathyroidism. ${ }^{24-26}$

In this article, we describe the procedure of HIFU for thyroid nodules ablation, as well as the available clinical results, efficacy, complications, and perspectives, based on the current evidence and our own experience.

\section{HIFU equipment}

The HIFU equipment (Echopulse ${ }^{\circledR}$; Theraclion, Paris, France) is a computer-controlled medical device comprised of an electronic cabinet and a visualization and treatment unit (VTU) with a cooling system and operational interactive touch screen (Figure 1)., ${ }^{9,24-27}$ The device is designed to provide HIFU treatment for superficial structures, notably thyroid nodules, parathyroid glands, or breast fibroadenomas. ${ }^{28}$

As described previously, the VTU incorporates both the imaging transducer (7.5 MHz, 128 elements, linear array) and the HIFU transducer ( $3 \mathrm{MHz}$, single element, $60 \mathrm{~mm}$ / diameter) for delivering energy to the target. ${ }^{9}$

The HIFU energy is delivered via the VTU system through the skin and is focused on a portion of the targeted tissue, generating intense heat and causing ablation within the focal area. The process is then repeated in a stepwise fashion to destroy the whole target tissue.

The treatable area lies between 5 and $28 \mathrm{~mm}$ from the skin and the intended size of the HIFU ablation unit is $9 \mathrm{~mm}$ in length and $2 \mathrm{~mm}$ in diameter (Figure 2). The safety of the adjacent structures is ensured by a laser-based movement detector that enables immediate power interruption in case of patient's movement or swallowing.

\section{Inclusion and exclusion criteria}

The objectives of HIFU ablation are to reduce the thyroid nodules' volume, prevent the nodules' growth, and normalize thyroid function in cases with autonomously functioning nodules. The procedure is suitable also for patients who

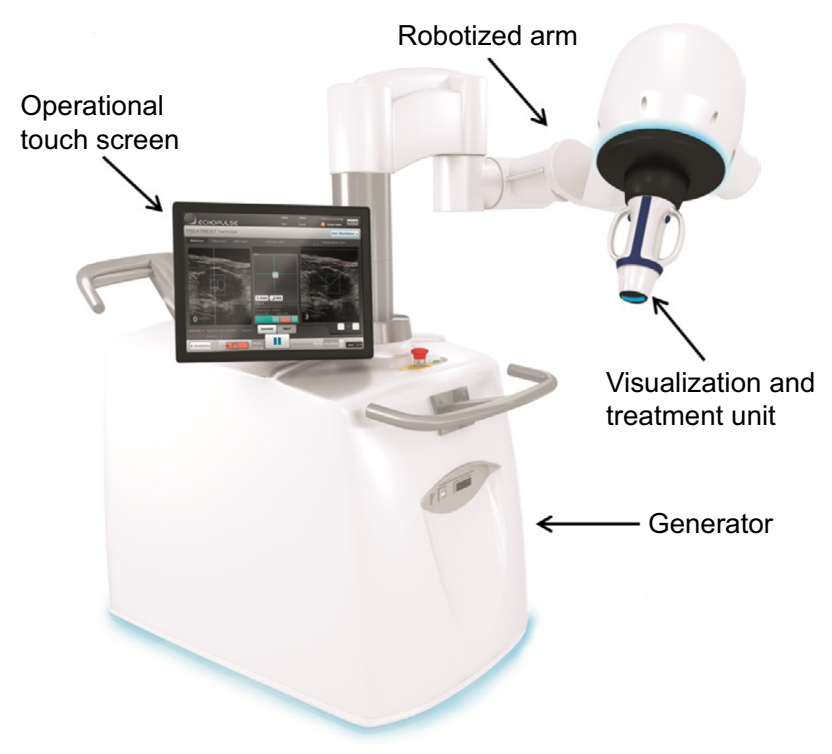

Figure I US-guided HIFU device (Echopulse ${ }^{\circledR}$; Theraclion, Paris, France). Abbreviations: US, ultrasound; HIFU, high-intensity focused ultrasound.

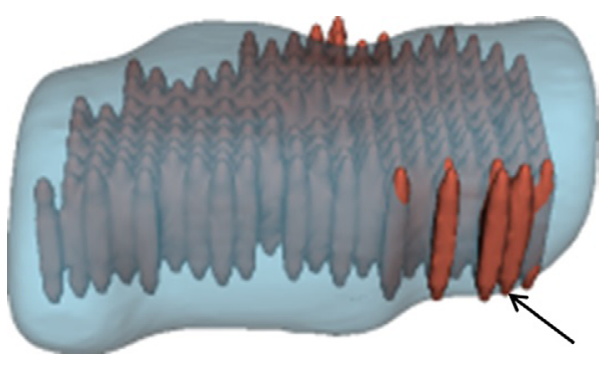

Figure 2 3D model of thyroid nodule with conceptual HIFU ablation units. Note: The ensemble of treatment units (black arrow) forms a treatment layer. Abbreviations: 3D, three dimensional; HIFU, high-intensity focused ultrasound. 
refuse operative resection due to medical comorbidities or recurrence after previous thyroid surgery.

Most studies on HIFU treatment of thyroid nodules performed until now were usually based on the following inclusion criteria: 1) age over 18 years, 2) presence of solitary or dominant thyroid nodule without signs of malignancy (non-suspicious clinical and US appearance, benign cytology performed in the last 6 months, normal serum calcitonin), 3) less than $30 \%$ of cystic area in the targeted nodule, and 4) absence of vocal cord immobility at laryngoscopy. ${ }^{9,23,29}$ The specific technical requirements include 1) nodule size $>10 \mathrm{~mm}$ in all directions and $\leq 35$ $\mathrm{mm}$ in transversal and longitudinal US scan, 2) HIFU accessibility of targeted nodule (distance between the skin and the anterior surface of the nodule $<17 \mathrm{~mm}$, no interference of collarbone with HIFU unit movements), 3) no intranodular macrocalcifications inducing a substantial shadow to preclude the HIFU treatment, and 4) no vulnerable structures (carotid artery, trachea, recurrent laryngeal nerve) on the beam pathway.

Exclusion criteria were usually as follows: 1) head and/ or neck disease preventing hyperextension of neck, 2) history of thyroid cancer or other malignancies in the neck region, 3) history of neck irradiation, 4) pregnancy, and 5) any contraindication related to local or intravenous moderate sedation. ${ }^{9,23,29}$

\section{Pre-procedural evaluation}

US examination is the most important for the evaluation of nodule characteristics, the surrounding structures, and the treatment parameters. The maximum nodule diameters should be measured in three orthogonal planes and the nodule volume could be calculated by using the ellipsoid model (width $\times$ length $\times$ thickness $\times \pi / 6$ ). The distance between the skin and the anterior nodule surface should also be estimated. The nodule composition and echogenicity has to be defined by the examiner as solid hypoechoic, isoechoic, and hyperechoic before and after the treatment. Intranodular color flow Doppler pattern could be classified as previously described: type 0 , absence of flow; type I, presence of flow with patchy, uneven distribution; type II, clearly increased color Doppler signal with patchy distribution; and type III, marked increase in blood flow with diffuse homogeneous distribution. ${ }^{30}$ USguided fine-needle biopsy with cytology is necessary to confirm the nature of the targeted nodule.

Laboratory tests usually include evaluation of thyroid function (thyrotropin, free thyroxine, and free triiodothyronine), thyroid autoimmunity (thyroid peroxidase and thyroglobulin (Tg) antibodies), and serum calcitonin. Indirect laryngoscopy is recommended to be performed on all patients before the treatment to assess the vocal cord mobility.

Clinical symptoms may be subjectively rated on a 0-10 cm visual analog scale and a cosmetic score could be evaluated by a physician using $1-4$ grade scale (1, no palpable nodule; 2 , palpable but not visible nodule; 3 , visible nodule on swallowing; 4 , readily visible nodule). ${ }^{31}$

Each patient should be informed about the procedure, the number of treatments, the expected results and side effects, and the duration of follow-up and should sign written informed consent.

\section{HIFU procedure}

HIFU ablation is performed on an outpatient basis, under local anesthesia or intravenous conscious sedation. The patient is placed in supine position with the head in moderate hyperextension, and a venous catheter is inserted in a forearm vein. During therapy, the patient's heart rate, blood pressure, respiration rate, and peripheral oxygenation are monitored. Patients are asked to make a sign (shake hand) in case of pain or increased pressure from the treatment device.

The treatment procedure consists of 6 steps: 1) pretreatment ultrasonography: this is performed with a handheld transducer, to acquire reference images of the thyroid nodule; 2) VTU positioning: the VTU is manually put on the patient's neck to set the point of the treatment cone in the middle of the target and to check the VTU coverage of the whole treatment volume without interfering with the trachea, carotid artery, and collarbone; 3 ) treatment planning: the target and the zones of interest (skin, trachea, esophagus, and carotid artery) are outlined on the screen in two axes by the physician; based on this information, the target is automatically divided in multiple ablation units and the software excludes those that are outside the defined safety margins from the treatment plan (Figure 3A and B); 4) energy setting: the first test pulse is delivered in the center of the targeted nodule with a predefined energy level, which is thereafter individually adjusted according to the appearance of hyperechoic marks at the focus point (Figure 3C); when hyperechoic marks do not appear at maximal admissible energy, the treatment is continued at submaximal level in order to avoid extranodular thermal damage; 5) generation of HIFU treatment pulses: after the energy adjustment, the treatment starts and the VTU automatically moves from site to site to deliver the defined energy; treatment duration depends on the nodule volume and includes time for sonication (4 seconds per ablation site), time for cooling (usually 15-40 seconds per pulse, which depends on the energy power and the nodule distance from 


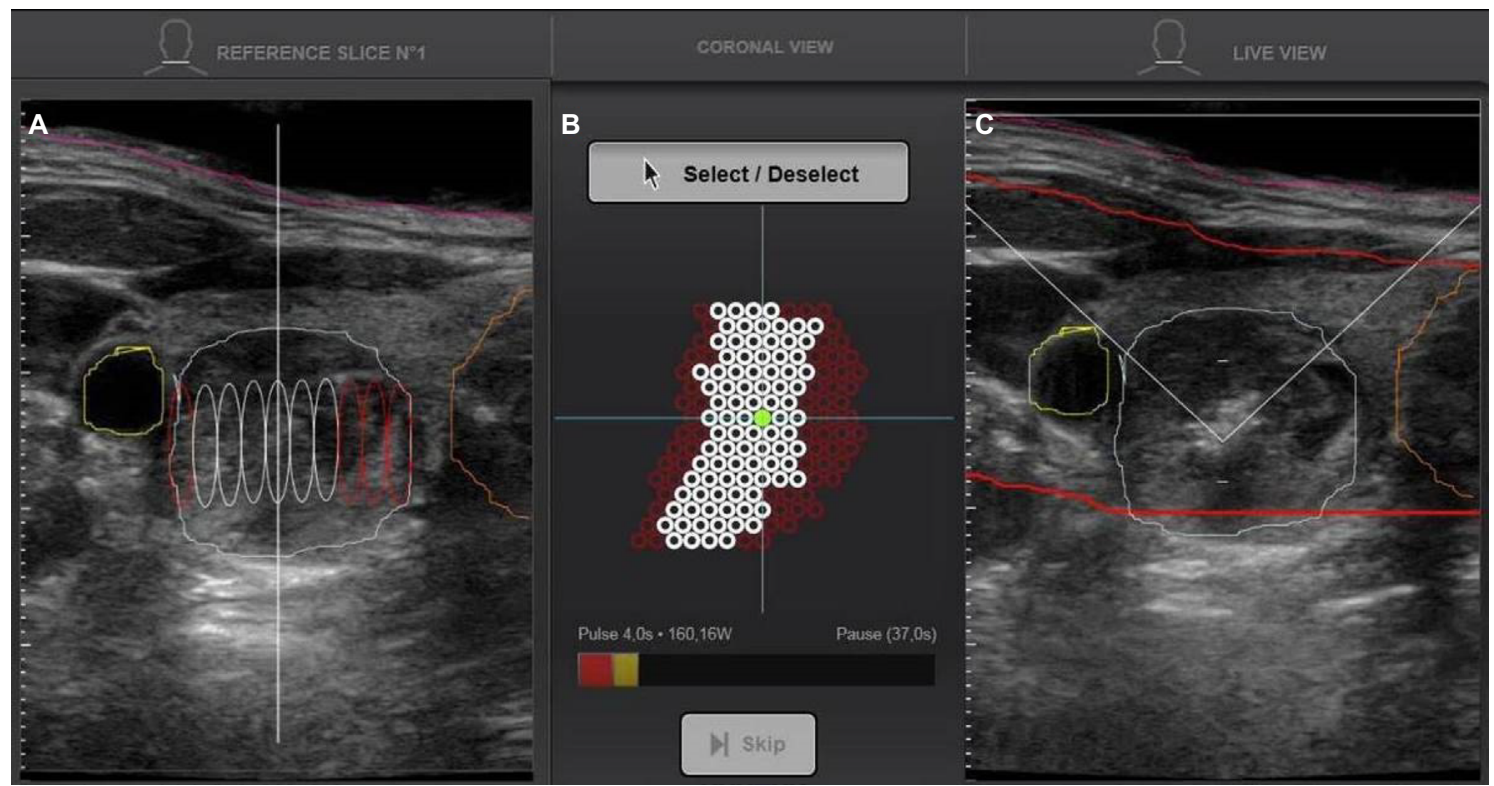

Figure 3 Treatment planning and setting of the energy.

Notes: (A) The ablation units outside of the safety margins are automatically eliminated by the software (in red color). (B) Schematic presentation of all sites intended to treatment; excluded sites are red in color, the sites that will be treated are white in color, and after they receive the pulse, they become green. (C) Visualization of hyperechoic mark (white spot) on the point of the treatment cone after the first sonication.

the skin), and time for repositioning (if the patient moves or swallows); and 6) post-treatment visualization: US and color Doppler images are recorded at the end of the treatment using the handheld transducer.

\section{Follow-up}

After the treatment the patients usually remain under observation up to 2 hours in a recovery room with an ice pack on the neck. In case of voice change or swallowing problems, the vocal cord mobility should be assessed with indirect laryngoscopy 24 hours after the procedure.

Follow-up US examinations are recommended after 1, 3 , and 6 months to record the changes in thyroid nodule volume, echogenicity, and vascularization and to assess the need to repeat the treatment. Further follow-up could be performed at 6- or 12-month intervals, depending on individual case.

\section{Clinical efficacy}

Clinical data on the thyroid nodule ablation are limited to 5 human studies in 4 different research centers in Europe, working with the same equipment. 9,23,27,32

A case report on a single hyperfunctioning nodule demonstrated that 2 weeks after HIFU treatment, the nodule appearance was cystic at US. ${ }^{33}$ Thyroid function normalized after 3 months and was maintained during the follow-up to 18 months. At US examination, the treated nodule appeared as a thin hypoechoic lesion devoid of vascular signals, and thyroid scintiscan showed functional recovery of the surrounding thyroid tissue.

In an open feasibility study, Esnault et al performed HIFU in 25 patients 2 weeks before surgery for nodular goiter. ${ }^{23}$ Histological examinations revealed that the damage was limited to the treated lesions with a nodule necrosis that ranged from 2 to $80 \%$. The authors used no sedation in 6 patients, local anesthesia in 13 patients, and general anesthesia in 6 patients.

Leenhardt et al compared nodule volume changes in 21 patients treated with HIFU and 11 nontreated patients with 13 nodules as a control group in a single-center randomizedcontrol study. ${ }^{32}$ The median treatment duration was 52 minutes. At 6-month follow-up, the nodule volume shrinkage was significantly higher in the HIFU group than in the controls. Only $23.8 \%$ of the treated patients were still symptomatic, while no change was found in the control group. Thyroid function in treated patients was not altered.

Korkusuz et al assessed HIFU treatment success in 10 patients with solid and complex nodules, 6 cold, and 4 hot or indifferent at scintiscan, with a repeated scintigraphy 1 day after the ablation. ${ }^{34}$ They found a significant nodular ${ }^{99 \mathrm{~m}} \mathrm{Tc}$-methoxy-isobutyl-isonitrile uptake reduction, with a $35.5 \%$ reduction in median uptake for cold nodules and $27 \%$ reduction in median uptake at ${ }^{99 \mathrm{~m}} \mathrm{Tc}$-pertechnetate scintigraphy for hot or indifferent nodules. The treatment did not affect thyroid function and no serious immune reaction was observed, despite the significant rise in serum Tg level 1 day after the ablation. ${ }^{27,35}$ Patients received either local anesthesia 
or no anesthesia at all and the average treatment duration was $68 \pm 21$ minutes. Nine patients were followed 3 months after HIFU procedure and the median volume reduction was $48.8 \%$ (range, 11.4-75\%), without correlation to pretreatment nodule volume, echographic structure, and total delivered energy. Significant negative correlation was found between absolute nodule shrinkage and the average treatment depth as well as with nodular uptake reduction. ${ }^{29}$

In a prospective uncontrolled study, Kovatcheva et al evaluated the efficacy and safety of US-guided HIFU for the treatment of benign solid thyroid nodules. ${ }^{9}$ Twenty euthyroid patients with a solitary or dominant nodule in a multinodular goiter received single HIFU procedure under conscious sedation with mean treatment duration of $86.8 \pm 31.7$ minutes. All the patients were assessed for thyroid nodule volume, structure, and vascularization at baseline, 1 week, and 1 and 3 months after the treatment, while 16 patients were assessed for nodule characteristics at 6 months. The nodule volume reduced significantly as early as at 1-month follow-up and the mean volume reduction at 6 months was $48.7 \%$ with maximal shrinkage of $92.9 \%$ (Figure 4 ). There was no significant correlation with basal volume, treatment death, and the applied energy per volume tissue.

The mean cosmetic score decreased significantly from $2.6 \pm 1.0$ to $1.9 \pm 0.9$ and the patient's satisfaction was rated $8.8 \pm 2.0$ (range $3-10)$ using visual analog scale $(0-10 \mathrm{~cm})$. One week after the treatment, no change was observed in the structure of initially hypoechoic nodules but most of the isoechoic nodules changed to hypoechoic. At the same time, nodule vascularity significantly decreased and remained significantly lower 3 and 6 months after therapy. ${ }^{9}$
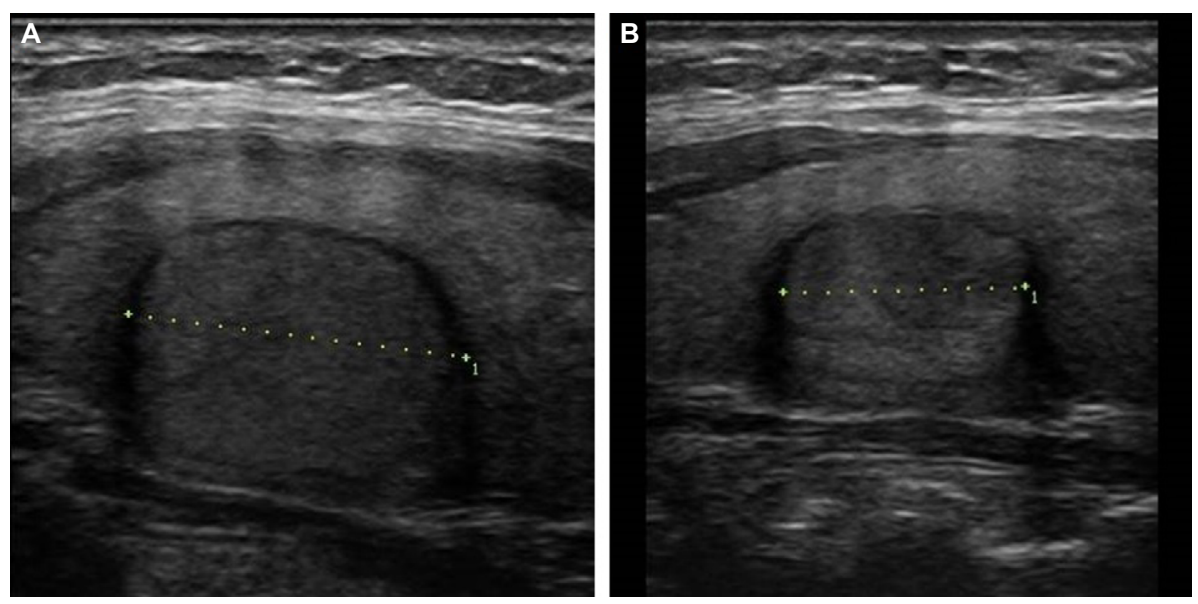

Figure 4 Early results after HIFU treatment - US follow-up.

Notes: (A) Longitudinal B scan of a $3.3 \mathrm{~mL}$ hypoechoic solid thyroid nodule at baseline. (B) Six months after the treatment, the volume reduction was $45.3 \%$. Abbreviations: US, ultrasound; HIFU, high-intensity focused ultrasound.
The same center also reported long-term results of one (group 1) and two (group 2) consecutive HIFU treatments of solid benign thyroid nodules. ${ }^{36,37}$ Twelve months after the last HIFU procedure, they found mean volume reduction of $\geq 50 \%$ in both groups (Figure 5). Preliminary data from a recent study with a new version of HIFU device (Beamotion ${ }^{\circledR}$; Theraclion, Paris, France) showed similar early effects on thyroid nodule volume with 4 -fold shorter treatment duration. ${ }^{38}$ The authors observed transient changes in thyroid hormones and serum Tg at 1 week, which correlated significantly with the total applied energy and the volume reduction. They supposed the possible use of these parameters as ablation markers and predictors of treatment effect.

\section{Side effects and complications}

The reported side effects of HIFU ablation have not been serious and major complications are uncommon. Burning pain is the most common complaint during the procedure, but it appears in the last 2-3 seconds of HIFU pulse and is usually tolerated by the patients. Some patients described a spreading of pain towards the neck, scapula, trapezius muscle, or arm. ${ }^{29}$ Analgesics were not needed in the posttreatment period..$^{9,27,32}$ Most of the authors reported mild skin redness and subcutaneous edema that spontaneously disappeared few days after the treatment.9,23,29 Esnault et al observed mild skin burn and also cough in 2 patients during the treatment. ${ }^{23}$ A small hematoma developed at the injection site of the local anesthetic in 1 patient. ${ }^{29}$ Leenhardt et al reported about 1 patient with transient vocal cord palsy that resolved after 2 weeks. ${ }^{32}$ In a recent report, Kovatcheva et al described a case of Horner syndrome, with a total recovery after 6 months. ${ }^{37}$ 

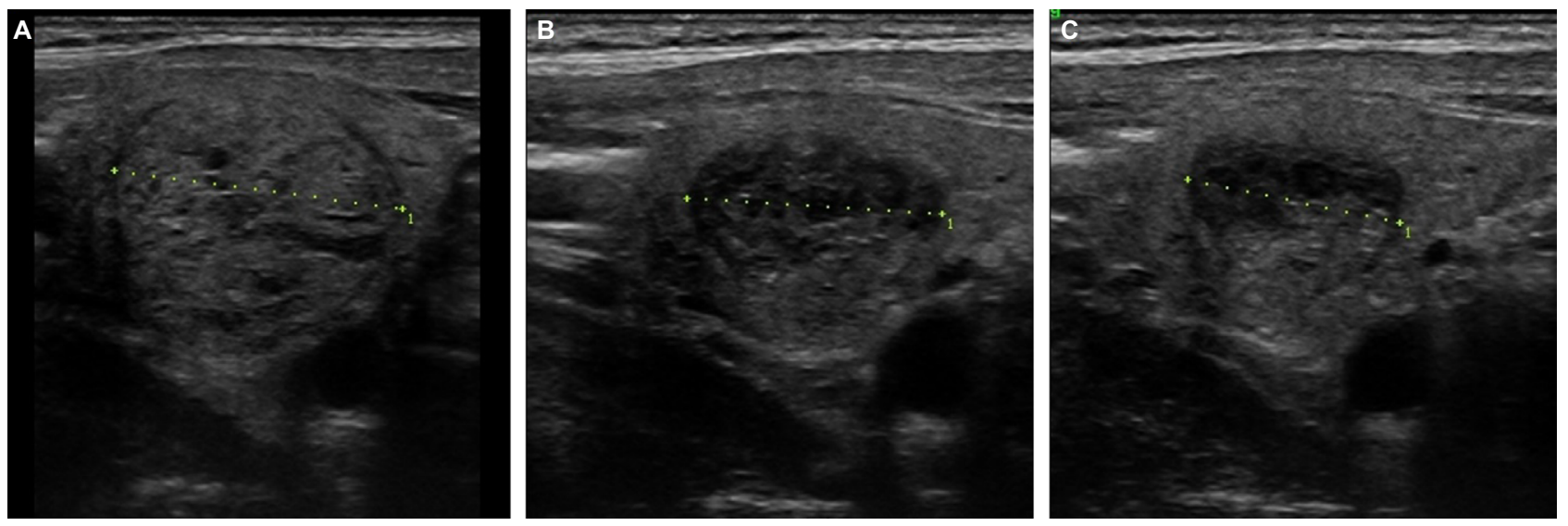

Figure 5 Long-term results after HIFU ablation.

Notes: (A) Longitudinal B scan of a $5.9 \mathrm{~mL}$ isoechoic solid thyroid nodule at baseline. (B) At 6-month follow-up, $67 \%$ of volume reduction was found. (C) Twelve months after the treatment, the nodule volume was $1.9 \mathrm{~mL}$ and the volume reduction was $71.7 \%$.

Abbreviations: US, ultrasound; HIFU, high-intensity focused ultrasound.

\section{Discussion}

Various nonsurgical treatment methods for benign thyroid nodules have been largely considered in the recent years. Despite different approach and study design, US-guided HIFU technique has demonstrated $48.7 \%$ efficacy in nodule volume reduction at 6 months, which is comparable with the other ablative therapies. Six months after a single radiofrequency ablation procedure, the nodule volume diminished from 51 to $85 \% .{ }^{16}$ Longer follow-up after laser ablation therapy showed a volume reduction of $47.8-51 \%{ }^{39,40}$ Feng et al reported $46 \%$ of nodule shrinkage 12 months after microwave ablation. ${ }^{18}$ All procedures listed here are minimally invasive.

HIFU appears as the only noninvasive procedure due to the absence of skin penetration. Compared with surgery or other nonsurgical methods, fewer side effects are observed in HIFU-treated patients. In unilateral or bilateral thyroid surgery, total complication rate was $8 \%$ and $26 \%$, respectively. ${ }^{41}$ Besides, in the majority of patients, L-thyroxine substitution was obligatory. HIFU ablation is limited to the targeted nodule and has no influence on thyroid function according to the current data. ${ }^{32,37,38}$ Even more, the treatment could be safely repeated in case of insufficient efficacy or nodule regrowth.

In radiofrequency or laser ablation, the most frequent complications are recurrent laryngeal nerve palsy or hematoma, whereas edema, skin burn, fevers, or trachea injury are rarely reported. ${ }^{16,19,42}$ The subcutaneous edema after HIFU treatment might be explained with the increased prefocal heat deposition as a result of fat tissue attenuation. Injury of recurrent laryngeal or sympathetic nerves is one of the major risks in thermal ablation therapies related to the propagation of heat outside the targeted nodule. According to the current evidence, these complications are transient and may be prevented by excluding the intended ablation sites adjacent to the nerves. ${ }^{19,32,37}$

Although the effect of US-guided HIFU therapy has become visible in a longer period, the main advantage to surgery is the performance in outpatient base, with only local anesthesia or conscious sedation, or no anesthesia at all, as well as the short recovery time. ${ }^{9,29}$

The HIFU technique has also shortcomings. In comparison with the other ablative procedures, the overall HIFU treatment duration is longer, which is associated with the regular intervals for cooling and pauses for repositioning after incidental patient movements. ${ }^{9}$ Recent device innovations have demonstrated shorter treatment duration with similar effect on nodule volume. ${ }^{38}$ Second, both the security margins around the sensible structures and the limitation to only one layer of treatment sites with a fixed anteroposterior size lead to partial ablation of the targeted nodule volume. Therefore, in larger nodules, the results may not be satisfactory. However, in case of insufficient volume reduction, a second treatment could be accomplished. Another solution is to perform the treatment in two layers, which is acceptable in the conditions of shorter treatment duration. Finally, the use of US beams as a treatment modality is connected to a restriction on the treatment depth to approximately $35 \mathrm{~mm}$ and is a major obstacle in patient selection for this application.

\section{Conclusion}

In conclusion, US-guided HIFU ablation is effective and safe noninvasive treatment method for benign solid thyroid nodules. However, more data on outcomes should be accumulated, especially long-term follow-up results from larger controlled and randomized studies with well-estab- 
lished selection criteria in order to define the spectrum of thyroid pathologies most suitable for this treatment. Comparable studies with other techniques as laser, radiofrequency, and microwave ablation will also be of interest. In the future, new indications should be considered, such as autonomously functioning nodules, recurrent Graves' disease, nodules with undetermined or suspicious cytology and even thyroid microcarcinoma.

\section{Disclosure}

The authors report no conflicts of interest in this work.

\section{References}

1. Haugen BR, Alexander EK, Bible KC, et al. 2015 American Thyroid Association management guidelines for adult patients with thyroid nodules and differentiated thyroid cancer: the American Thyroid Association guidelines task force on thyroid nodules and differentiated thyroid cancer. Thyroid. 2016;26(1):1-133.

2. Tunbridge WM, Evered DC, Hall R, et al. The spectrum of thyroid disease in a community: the Whickham survey. Clin Endocrinol (Oxf). 1977;7(6):481-493.

3. Tan GH, Gharib H. Thyroid incidentalomas: management approaches to nonpalpable nodules discovered incidentally on thyroid imaging. Ann Intern Med. 1997;126(3):226-231.

4. Guth S, Theune U, Aberle J, Galach A, Bamberger CM. Very high prevalence of thyroid nodules detected by high frequency $(13 \mathrm{MHz})$ ultrasound examination. Eur J Clin Invest. 2009;39(8):699-706.

5. Hegedüs L, Bonnema SJ, Bennedbaek FN. Management of simple nodular goiter: current status and future perspectives. Endocr Rev. 2003;24(1):102-132.

6. Gharib H, Papini E. Thyroid nodules: clinical importance, assessment, and treatment. Endocrinol Metab Clin North Am. 2007;36(3):707-735.

7. Erdogan MF, Gursoy A, Erdogan G. Natural course of benign thyroid nodules in a moderately iodine-deficient area. Clin Endocrinol (Oxf). 2006;65(6):767-771.

8. Longo M, Cassoli IP, Fugazzola L, Vannucchi G, Lanzoni M, Castaldi S. Feasibility study for the introduction of a new treatment method for benign thyroid nodules in a teaching and research hospital. J Eval Clin Pract. 2014;20(5):617-621.

9. Kovatcheva RD, Vlahov JD, Stoinov JI, Zaletel K. Benign solid thyroid nodules: US-guided high-intensity focused ultrasound ablation-initial clinical outcomes. Radiology. 2015;276(2):597-605.

10. Bergenfelz A, Jansson S, Kristoffersson A, et al. Complications to thyroid surgery: results as reported in a database from a multicenter audit comprising 3,660 patients. Langenbecks Arch Surg. 2008;393(5):667-673.

11. Gibelin H, Sierra M, Mothes D, et al. Risk factors for recurrent nodular goiter after thyroidectomy for benign disease: case-control study of 244 patients. World J Surg. 2004;28(11):1079-1082.

12. Pelizzo MR, Merante Boschin I, Toniato A, Sorgato N, Marzola MC, Rubello D. Surgical therapeutic planning options in nodular goiter. Minerva Endocrinol. 2010;35(3):173-185.

13. Bonnema SJ, Fast S, Hegedüs L. The role of radioiodine therapy in benign nodular goitre. Best Pract Res Clin Endocrinol Metab. 2014; 28(4):619-631.

14. Sung JY, Baek JH, Kim KS, et al. Single-session treatment of benign cystic thyroid nodules with ethanol versus radiofrequency ablation: a prospective randomized study. Radiology. 2013;269(1):293-300.

15. Gharib H, Hegedüs L, Pacella CM, Baek JH, Papini E. Clinical review: nonsurgical, image-guided, minimally invasive therapy for thyroid nodules. J Clin Endocrinol Metab. 2013;98(10):3949-3957.
16. Baek JH, Lee JH, Valcavi R, Pacella CM, Rhim H, Na DG._Thermal ablation for benign thyroid nodules: radiofrequency and laser. Korean J Radiol. 2011;12(5):525-540.

17. Achille G, Zizzi S, Di Stasio E, Grammatica A, Grammatica L. Ultrasound-guided percutaneous laser ablation in treating symptomatic solid benign thyroid nodules: our experience in 45 patients. Head Neck. 2016;38(5):677-682.

18. Feng B, Liang P, Cheng Z, et al. Ultrasound-guided percutaneous microwave ablation of benign thyroid nodules: experimental and clinical studies. Eur J Endocrinol. 2012;166(6):1031-1037.

19. Baek JH, Lee JH, Sung JY, et al; Korean Society of Thyroid Radiology. Complications encountered in the treatment of benign thyroid nodules with US-guided radiofrequency ablation: a multicenter study. Radiology. 2012;262(1):335-342.

20. Zhou YF. High intensity focused ultrasound in clinical tumor ablation. World J Clin Oncol. 2011;2(1):8-27.

21. Esnault O, Franc B, Monteil JP, Chapelon JY. High-intensity focused ultrasound for localized thyroid-tissue ablation: preliminary experimental animal study. Thyroid. 2004;14(12):1072-1076.

22. Esnault O, Franc B, Chapelon JY. Localized ablation of thyroid tissue by high-intensity focused ultrasound: improvement of noninvasive tissue necrosis methods. Thyroid. 2009;19(10):1085-1091.

23. Esnault O, Franc B, Ménégaux F, et al. High-intensity focused ultrasound ablation of thyroid nodules: first human feasibility study. Thyroid. 2011;21(9):965-973.

24. Kovatcheva RD, Vlahov JD, Shinkov AD, et al. High-intensity focused ultrasound to treat primary hyperparathyroidism: a feasibility study in four patients. AJR Am J Roentgenol. 2010;195(4):830-835.

25. Kovatcheva RD, Vlahov JD, Stoinov JI, et al._High-intensity focussed ultrasound (HIFU) treatment in uraemic secondary hyperparathyroidism. Nephrol Dial Transplant. 2012;27(1):76-80.

26. Kovatcheva R, Vlahov J, Stoinov J, Lacoste F, Ortuno C, Zaletel K. USguided high-intensity focused ultrasound as a promising non-invasive method for treatment of primary hyperparathyroidism. Eur Radiol. 2014;24(9):2052-2058.

27. Korkusuz H, Sennert M, Fehre N, Happel C, Grünwald F. Local thyroid tissue ablation by high-intensity focused ultrasound: effects on thyroid function and first human feasibility study with hot and cold thyroid nodules. Int J Hyperthermia. 2014;30(7):480-485.

28. Kovatcheva R, Guglielmina JN, Abehsera M, Boulanger L, Laurent N, Poncelet E. Ultrasound-guided high-intensity focused ultrasound treatment of breast fibroadenoma-a multicenter experience. $J$ Ther Ultrasound. 2015,3(1):1.

29. Korkusuz H, Fehre N, Sennert M, Happel C, Grünwald F. Volume reduction of benign thyroid nodules 3 months after a single treatment with high-intensity focused ultrasound (HIFU). JTher Ultrasound. 2015;3:4.

30. Vitti P, Rago T, Mazzeo S, et al. Thyroid blood flow evaluation by color-flow Doppler sonography distinguishes Graves' disease from Hashimoto's thyroiditis. J Endocrinol Invest. 1995;18(11):857-861.

31. Huh JY, Baek JH, Choi H, Kim JK, Lee JH. Symptomatic benign thyroid nodules: efficacy of additional radiofrequency ablation treatment session--prospective randomized study. Radiology. 2012;263(3):909-916.

32. Leenhardt L, Rouxel A, Menegaux F, Esnault O. An open-label, randomized, controlled study of the effectiveness and safety of a high intensity focused ultrasound device compared with observation in patients with non-malignant cold thyroid nodules. Endocrine Abstracts. 2013;32:P1013.

33. Esnault O, Rouxel A, Le Nestour E, Gheron G, Leenhardt L. Minimally invasive ablation of a toxic thyroid nodule by high-intensity focused ultrasound. AJNR Am J Neuroradiol. 2010;31(10):1967-1968.

34. Korkusuz H, Fehre N, Sennert M, Happel C, Grünwald F. Early assessment of high-intensity focused ultrasound treatment of benign thyroid nodules by scintigraphic means. J Ther Ultrasound. 2014;2:18.

35. Korkusuz H, Sennert M, Fehre N, Happel C, Grünwald F. Localized thyroid tissue ablation by high intensity focused ultrasound: volume reduction, effects on thyroid function and immune response. Rofo. 2015; 187(11):1011-1015. 
36. Kovatcheva R, Vlahov J, Stoinov J, Zaletel K. Long-term results of USguided high-intensity focused ultrasound treatment of benign thyroid nodules. Endocrine Abstracts. 2015;37:GP25.01.

37. Kovatcheva RD, Vlahov JD, Stoinov JI, Zaletel K. The effect of one and two sessions of US-guided high-intensity focused ultrasound (HIFU) treatment on thyroid nodule volume and thyroid function. Thyroid. 2015;25(Suppl 1):S176-S177.

38. Kovatcheva RD, Vlahov JD, Zaletel K, Shinkov A, Stoinov JI, Ivanova RB, Kirilov G. Functional and serum thyroglobulin changes after US-guided HIFU ablation of benign solid thyroid nodules in euthyroid patients. Eur Thyroid J. 2016;5(Suppl 1): $57-176$.
39. Valcavi R, Riganti F, Bertani A, Formisano D, Pacella CM. Percutaneous laser ablation of cold benign thyroid nodules: a 3-year follow-up study in 122 patients. Thyroid. 2010;20(11):1253-1261.

40. Døssing H, Bennedbæk FN, Hegedüs L. Long-term outcome following interstitial laser photocoagulation of benign cold thyroid nodules. Eur J Endocrinol. 2011;165(1):123-128.

41. Bauer PS, Murray S, Clark N, Pontes DS, Sippel RS, Chen H. Unilateral thyroidectomy for the treatment of benign multinodular goiter. J Surg Res. 2013;184(1):514-518.

42. Di Rienzo G, Surrente C, Lopez C, Quercia R. Tracheal laceration after laser ablation of nodular goitre. Interact Cardiovasc Thorac Surg. 2012;14(1):115-116.

\section{Publish your work in this journal}

Reports in Medical Imaging is an international, peer-reviewed, open access journal publishing original research, reports, reviews and commentaries on all areas of medical imaging. The manuscript management system is completely online and includes a very quick and fair peer-review system, which is all easy to use.

\section{Dovepress}

Visit http://www.dovepress.com/testimonials.php to read real quotes from published authors. 